\title{
Induction of apoptosis of human macrophages in vitro by Legionella longbeachae through activation of the caspase pathway
}

\author{
NORIKO ARAKAKI, FUTOSHI HIGA, MICHIO KOIDE, MASAO TATEYAMA and ATUSHI SAITO \\ First Department of Internal Medicine, Faculty of Medicine, University of the Ryukyus, Okinawa, Japan
}

\begin{abstract}
The cytotoxicity of the facultative intracellular bacterium, Legionella longbeachae, an important cause of legionellosis, was characterised. Apoptosis was induced in HL-60 cells, a human macrophage-like cell line, during the early stages of infection and induction of apoptosis correlated with cytotoxicity. Apoptosis was confirmed by agarose gel electrophoresis of fragmented DNA, surface exposure of phosphatidylserine and propidium iodide labelling of host cell nuclei. The involvement of macrophage infectivity potentiator (Mip) protein, a known virulence factor of $L$. longbeachae, was also examined. A mip mutant of L. longbeachae induced apoptosis of HL-60 cells but failed to multiply intracellularly, suggesting that intracellular replication of L. longbeachae is not essential for the induction of apoptosis of HL-60 cells. Furthermore, induction of apoptosis of $L$. longbeachae-infected macrophages was mediated by activation of the caspase pathway but might be independent of tumour necrosis factor- $\alpha$ - and Fasmediated signal transduction pathways.
\end{abstract}

\section{Introduction}

Legionella longbeachae was first described as a new species of Legionellacae in 1981, following its isolation from a patient with pneumonia who resided in Long Beach, California [1]. Subsequently, L. longbeachae serogroup 1 was isolated from a patient in South Australia in 1987 [2] and this was followed by an outbreak of infection in the same Australian state $[3,4]$. Recently, c. $50 \%$ of all legionellosis in South Australia has been attributed to this species [3,5]. Epidemiological studies have shown that gardening is a major risk factor in acquiring L. longbeachae infection in Australia [6]. Australian potting soil is not sterilised during manufacture and contains a mixture of bacteria and free-living amoebae, which provides a suitable medium for growth of Legionella spp. [7]. The first culture-confirmed Japanese case of L. longbeachae pneumonia was reported in 1996 by Okazaki et al. [8]. The patient was a gardener and potting soil was considered as a possible source of infection. The presence of bacteria in various brands of Japanese potting soil has since been examined: 31 strains of Legionella spp. have been isolated from 17 Japanese

Received 22 Jan. 2001; revised version received 6 Aug. 2001; accepted 14 Aug. 2001.

Corresponding author: Dr N. Arakaki (e-mail: k970403 @med.u-ryukyu.ac.jp). potting soils, and 7 potting soils contained L. longbeachae [9].

Several investigators have shown that macrophage infectivity potentiator (Mip) protein plays an important role in the intracellular life cycle of L. longbeachae [5]. In L. pneumophila, the Mip protein is responsible for efficient initiation of intracellular infection of human macrophages, and a mip mutant was shown to be less infective for human macrophages, as well as for Acanthamoeba castellanii $[10,11]$. It was also reported that a mutation in mip resulted in attenuated virulence in guinea-pigs [11]. The Mip protein of L. pneumophila belongs to the enzyme family of peptidylprolyl cis-trans isomerases and is homologous to the FK506 binding protein [12]. A mip mutant of $L$. longbeachae serogroup 1 ATCC 33462 could not infect a strain of Acanthamoeba sp. Furthermore, the mip mutation resulted in reduced virulence in guinea-pigs exposed to aerosol infection [5].

In recent years, several bacterial pathogens have been identified as inducers of apoptosis (programmed cell death). The role of apoptosis differs with each type of bacterial infection. For example, in Shigella flexneri $[13,14]$ and Salmonella enterica serovar Typhimurium [15] infections, induction of apoptosis results not only in deletion of host cells but also in initiation of inflammation, by activating interleukin- $1 \beta$ converting 
enzyme. Several bacteria that produce exotoxins, like Corynebacterium diphtheriae [16], Pseudomonas spp. [16], Actinobacillus actinomycetemcomitans [17], Bacillus anthracis [18] and group A streptococci [19] induce apoptosis of macrophages before these cells can ingest and destroy the bacteria. Mycobacterium tuberculosis was reported to enhance apoptosis of alveolar macrophages by mechanisms involving tumour necrosis factor (TNF)- $\alpha$ [20]. On the other hand, M. bovis and Brucella suis prevent apoptosis of human monocytes [21-23] and seem to protect themselves from the host immune system in this way.

Previous studies have provided evidence for the induction of apoptosis in the HL-60 macrophage-like cell line by L. pneumophila [24]. The same organism induces apoptosis of alveolar epithelial cells during the early stages of infection and this plays an important role in its cytotoxicity [25]. However, apoptosis induced by other Legionella species has not been investigated. In this study, the ability of L. longbeachae to induce apoptosis and cytotoxicity in HL-60 cells was investigated.

\section{Materials and methods}

\section{Bacterial strains and growth conditions}

The strains used in this study are listed in Table 1. The mip mutant B10 of L. longbeachae serogroup (SG) 1 ATCC 33462, Australian clinical isolate of $L$. longbeachae SG1 A5H5 and the A5H5 mip mutant B8 were kindly provided by Robyn M. Doyle (University of Adelaide, South Australia, Australia) [5]. Strain SG1 96-003 was isolated from the first Japanese case of pneumonia caused by L. longbeachae [8]. The other strains (nos 98-066, 98-079, 98-082, 98083, and 98-084) were isolated from potting soils in Japan. L. pneumophila strain SG1 80-045 was isolated from the first Japanese patient identified to have Legionnaires' disease [26]. These strains were kept at $-80^{\circ} \mathrm{C}$ in sterile skimmed milk supplemented with sodium glutamate $1 \% \mathrm{w} / \mathrm{v}$. Before experiments, the

Table 1. Bacterial strains

\begin{tabular}{|c|c|c|}
\hline Strain & Relevant characteristic(s) & $\begin{array}{l}\text { Reference or } \\
\text { source }\end{array}$ \\
\hline \multicolumn{3}{|l|}{ L. longbeachae SG 1} \\
\hline ATCC 33462 & Type strain & $\mathrm{CDC}$ \\
\hline $96-003$ & Japanese clinical isolate & 8 \\
\hline $\begin{array}{l}98-066,98-079,98- \\
082,98-083,98-084\end{array}$ & $\begin{array}{l}\text { Japanese environmental } \\
\text { isolates }\end{array}$ & Present study \\
\hline A5H5 & Australian clinical isolate & 5 \\
\hline B8 & $\begin{array}{l}\text { A5H5 with a mip } \\
\text { deletion mutation }\end{array}$ & 5 \\
\hline B10 & $\begin{array}{l}\text { ATCC } 33462 \text { with a mip } \\
\text { deletion mutation }\end{array}$ & 5 \\
\hline \multicolumn{3}{|l|}{ L. pneumophila SG 1} \\
\hline $80-045$ & Japanese clinical isolate & 28 \\
\hline
\end{tabular}

ATCC, American Type Culture Collection, Rockville, MD, USA. CDC, Centers for Disease Prevention and Control, Atlanta, GA, USA. strains were cultured on buffered charcoal yeast extract- $\alpha$ (BCYE- $\alpha$ ) agar plates at $35^{\circ} \mathrm{C}$ for $48 \mathrm{~h}$, when a thin lawn of bacterial growth was visible [24]. The bacteria were then harvested and suspended in distilled water and their concentration was adjusted to c. $1 \times 10^{9} \mathrm{cfu} / \mathrm{ml}$ by optical density.

\section{HL-60 cell culture}

The human leukaemia cell line HL-60 [27] was maintained at $37^{\circ} \mathrm{C}$ in a medium consisting of RPMI 1640 (pH 7.2; Gibco Laboratories, Grand Island, NY, USA), $10 \mathrm{~mm}$ HEPES (Dojin Chemicals, Kumamoto, Japan) and heat-inactivated fetal calf serum (FCS; Whittaker, Walkersville, MD, USA) $10 \% \mathrm{v} / \mathrm{v}$ (RPMIFCS) in $75-\mathrm{cm}^{2}$ culture flasks (Falcon 3084; Nippon Becton Dickinson, Tokyo, Japan) in humidified air with $\mathrm{CO}_{2}$ 5\%. HL-60 cells were differentiated into macrophage-like cells by incubating them for 2 days with $10^{-8} \mathrm{M}$ phorbol 12-myristate 13-acetate (Sigma) in RPMI-FCS. Adherent cells were washed three times with RPMI-FCS and then incubated in this medium before infection.

\section{Infection of HL-60 cells}

Differentiated HL-60 cells, in triplicate, in 96-well microtitration plates containing $1 \times 10^{5}$ cells/well were infected with $L$. longbeachae strains at multiplicities of infection (MOIs; bacteria:macrophage) of 10 and 100 for $2 \mathrm{~h}$. At the end of the infection period (time 0 ), the monolayers were washed three times to remove unattached extracellular bacteria and maintained at $37^{\circ} \mathrm{C}$ in the culture medium for various incubation times $(0-$ $48 \mathrm{~h}$ ). The infected cell monolayers and supernates in each well were then harvested in $9.8 \mathrm{ml}$ of sterile distilled water, and the mixture was vortex mixed for $20 \mathrm{~s}$ to lyse the cells. These bacterial suspensions were diluted appropriately and $100-\mu 1$ samples of the dilutions were inoculated on to BCYE- $\alpha$ agar to determine the numbers of viable Legionellae in each well.

\section{Cytotoxicity assay}

After infection, washing and incubation of HL-60 cells for various times, as described above, cytotoxicity assays were done. The dye 3-(4,5-dimethylthiazole2-yl)-2,5-diphenyl tetrazolium bromide (MTT), $10 \mu \mathrm{l}$ at a concentration of $5 \mathrm{mg} / \mathrm{ml}$, was added to each well. The microtitration plates were incubated for $4 \mathrm{~h}$ at $37^{\circ} \mathrm{C}$, under $\mathrm{CO}_{2} 5 \%$ in air. The supernates were then removed and $100 \mu \mathrm{l}$ of isopropyl alcohol containing $0.04 \mathrm{~N} \mathrm{HCl}$ were added to each well. The plates were read on a microplate reader (model 550, BioRad Laboratories) at a wavelength of $550 \mathrm{~nm}$. The $\mathrm{A}_{550}$ values of triplicate wells were averaged to determine the extent of macrophage killing. The percentage cytotoxicity was calculated at each incubation time by the following formula: percentage cytotoxicity 
$=100 \times\left(1-\mathrm{A}_{550}\right.$ infected cells $/ \mathrm{A}_{550}$ uninfected cells).

\section{DNA fragmentation}

Differentiated HL-60 cells in 24-well plates containing $1 \times 10^{6}$ cells/well were infected with $L$. longbeachae strains at a MOI of 10 and 100 for $2 \mathrm{~h}$. At the end of the infection period, the monolayers were washed three times to remove unattached extracellular bacteria and maintained at $37^{\circ} \mathrm{C}$ in the culture medium. As a positive control for apoptosis or DNA fragmentation, cells were incubated in RPMI-FCS containing actinomycin D (ActD; Sigma) $1 \mu \mathrm{g} / \mathrm{ml}$. As a negative control, uninfected cells in RPMI-FCS underwent the same washing treatment. To assess whether the bacteria have to be viable to induce apoptosis, heat-inactivated bacteria were used for infection. A bacterial suspension was heated at $95^{\circ} \mathrm{C}$ for $30 \mathrm{~min}$, and complete killing was verified by plating on BCYE- $\alpha$. After incubation of HL-60 cells, the cells were lysed by addition of $100 \mu 1$ of lysis buffer (Triton X-100 0.5\%, $10 \mathrm{~mm}$ Tris, pH 7.4, 10 mM EDTA, pH 8.0) per well. After incubation for $10 \mathrm{~min}$ at $4^{\circ} \mathrm{C}$, samples were centrifuged for $20 \mathrm{~min}$ at $16000 \mathrm{rpm}$. The resulting supernates were digested with $2 \mu \mathrm{l}$ of RNAase $(20 \mathrm{mg} / \mathrm{ml})$ for $1 \mathrm{~h}$ at $37^{\circ} \mathrm{C}$, and then incubated for a further $1 \mathrm{~h}$ at $37^{\circ} \mathrm{C}$ with $2 \mu \mathrm{l}$ of proteinase $\mathrm{K}(20 \mathrm{mg} / \mathrm{ml})$. The lysates were further incubated with $20 \mu \mathrm{l}$ of $5 \mathrm{M} \mathrm{NaCl}$ and $120 \mu \mathrm{l}$ of isopropanol for $24 \mathrm{~h}$ at $-20^{\circ} \mathrm{C}$ to precipitate the DNA. After centrifugation the precipitates were dried to remove isopropanol and then solubilised in $10 \mathrm{mM}$ Tris$\mathrm{HCl}(\mathrm{pH} \mathrm{8.0)}$ and $1 \mathrm{mM}$ EDTA. Electrophoresis was performed in an agarose $2 \%$ gel, which was then stained with ethidium bromide.

Inhibition of DNA fragmentation in differentiated HL60 cells by the broad-specificity caspase inhibitor Z-VAD-FMK (Enzyme System Products) [28] was investigated. Cells were pretreated with the inhibitor $(100 \mu \mathrm{M})$ for $90 \mathrm{~min}$ before they were infected with $L$. longbeachae strain ATCC 33462 at a MOI of 100 for $2 \mathrm{~h}$ in the presence of the inhibitor, followed by washing of unattached extracellular bacteria and incubation for $3 \mathrm{~h}$ in the presence of the inhibitor.

\section{Quantification of apoptosis by flow cytometry}

Apoptotic cells were quantified by an assay based on detection of phosphatidylserine (PS) exposed on the outer leaflet of apoptotic cells in the early phase of apoptosis [29]. Cells were stained with fluoresceinconjugated annexin $\mathrm{V}$, which has a high affinity for membrane-exposed PS according to the data provided by the manufacturer (Annexin V FITC Kit, Coulter Immunotech, Tokyo, Japan). Propidium iodide (PI) allowed the discrimination of apoptotic from necrotic cells, as necrotic cells are characterised by loss of cell membrane integrity and staining by PI and simul- taneous binding of annexin V. Analysis was performed by flow cytometry (Coulter Immunotech).

\section{Measurement of TNF- $\alpha$}

Differentiated HL-60 cells were infected with $L$. longbeachae as described above. After various incubation times, the concentrations of TNF- $\alpha$ were determined by enzyme-linked immunosorbent assay (ELISA) with a commercial kit according to the manufacturer's instructions (Biosource International, Camarillo, USA). In selected experiments, anti-human TNF- $\alpha$ (IgG fraction) (Sigma; $10 \mathrm{ng} / \mathrm{ml}$ ) was added $1 \mathrm{~h}$ before infection.

\section{Detection of Fas expression}

Fas expression on the surface of differentiated HL-60 cells was measured by flow cytometry. Uninfected and infected cells $\left(5 \times 10^{5}\right)$ were stained with $20 \mu \mathrm{l}$ of FITC-conjugated anti-Fas monoclonal antibody (MAb; Medical \& Biological Laboratories, Nagoya, Japan) in PBS containing FCS $1 \% \mathrm{v} / \mathrm{v}$ for $30 \mathrm{~min}$ at $4^{\circ} \mathrm{C}$. As a negative control, cells were stained with mouse IgG1FITC (Coulter Immunotech). Cells were then analysed by flow cytometry.

\section{Results}

Intracellular growth and cytotoxicity of $L$. longbeachae in macrophage-like HL-60 cells

Macrophage-like HL-60 cells were infected with L. longbeachae wild strain ATCC 33462 at MOIs of 10 and 100 . No detectable intracellular replication of the bacterium was observed by $6 \mathrm{~h}$ after infection at either MOI. After incubation for $12 \mathrm{~h}$, intracellular replication of L. longbeachae was observed (Fig. 1a). The cytotoxicity of L. longbeachae ATCC 33462 was tested by the MTT viability assay. The bacterium killed the HL-60 cells and the cytotoxic effect was dosedependent, with the maximal toxicity $(74.3 \% \pm 1.3 \%)$ noted at a MOI of 100 at $48 \mathrm{~h}$ after infection (Fig.1b).

Similar results were obtained by infection of a clinical isolate of L. pneumophila, strain 80-045, and other Japanese isolates of L. longbeachae under the same conditions (data not shown). The cytotoxic activities of the Australian clinical isolate A5H5 of L. longbeachae and its mip mutant were also compared (Fig. 2). The mip mutant strain B8 exhibited a similar level of cytotoxicity compared to the wild-type strain in the later stages of infection (24 and $48 \mathrm{~h}$ after infection). However, at the earlier stage of infection $(6 \mathrm{~h}$ after infection), strain $\mathrm{A} 5 \mathrm{H} 5$ was more cytotoxic than strain B8 (15.5\% and $-7.2 \%$, respectively).

\section{Apoptosis of L. longbeachae-infected HL-60 cells}

DNA fragmentation is a unique event of apoptosis. 

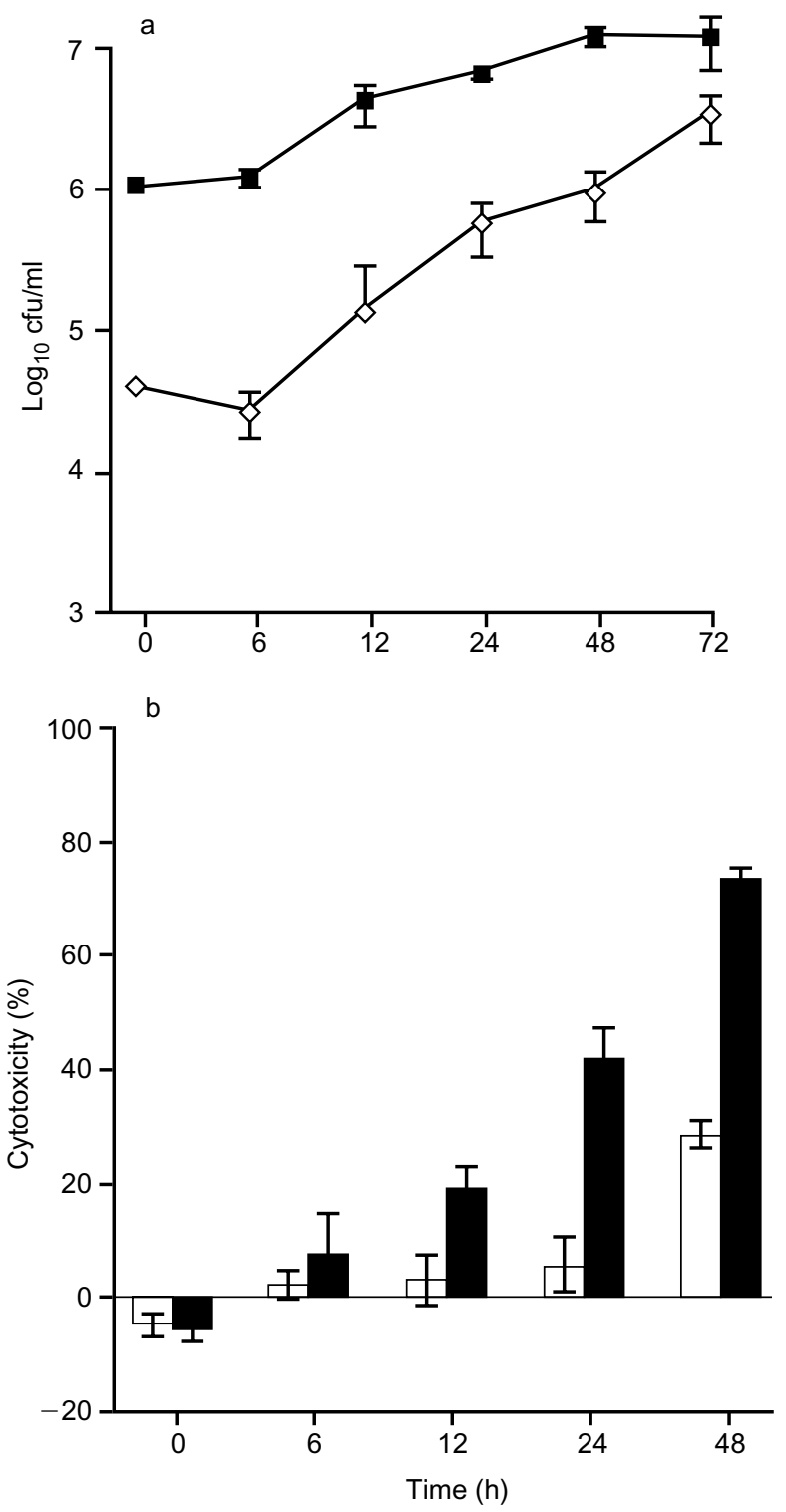

Fig. 1. (a) Intracellular growth kinetics of $L$. longbeachae ATCC 33462 in macrophage-like HL-60 cells. Cells were infected with the bacteria at MOIs of $10(\diamond)$ and $100(\mathbb{\square})$ for $2 \mathrm{~h}$; the numbers of intracellular bacteria were determined at intervals thereafter. (b) Cytotoxic effect of L. longbeachae ATCC 33462 on macrophage-like HL-60 cells. Cytotoxicity was determined by the MTT assay at different times after infection at MOIs of $10(\square)$ and $100(\square)$. Data are the means and SD of triplicate wells and are representative of three experiments.

Apoptosis of L. pneumophila-infected HL-60 cells has been observed at 24-48 h after infection at MOIs of 10 and 50 [24]. Apoptosis of U937 macrophages by L. pneumophila was also reported during the early stages of infection at MOIs of $0.5,5$, and 50 when various methods were used to identify apoptosis [25]. Based on these early studies, apoptosis of L. longbeachae-infected macrophage-like HL-60 cells was examined by agarose gel electrophoresis to detect DNA fragmentation. The DNA from macrophage-like HL-60 cells that had been infected with live $L$. longbeachae for $24-48 \mathrm{~h}$ showed the typical nucleosome pattern of DNA ladder formation (Fig. 3). The

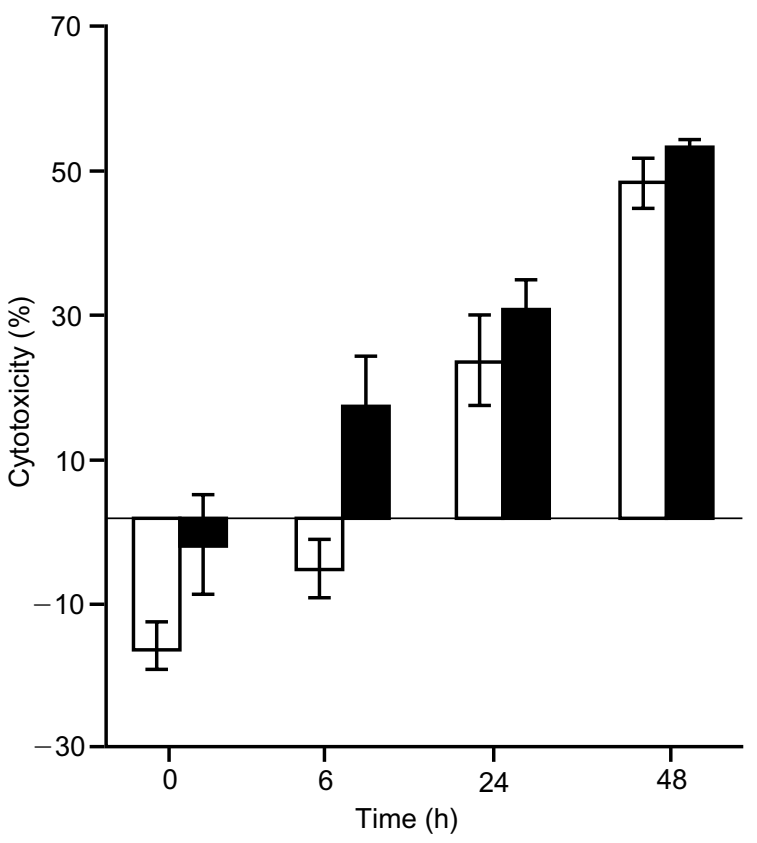

Fig. 2. Comparison of the cytotoxicity of $L$. longbeachae strain A5H5 (ם) and strain B8 ( $\square$ ), a mip mutant derivative of A5H5. HL-60 cells were infected at a MOI of 100. Data are the means and SD of triplicate wells and are representative of three experiments.

pattern of the DNA ladder was similar to that in actinomycin-D-treated cells (positive control), whereas the DNA pattern of cells treated with heat-inactivated bacteria was similar to that of uninfected cells (negative control), which exhibited mainly intact DNA (Fig. 3). The DNA from HL-60 cells infected with $L$. pneumophila 80-045 and other Japanese isolates of $L$. longbeachae also showed ladder formation (data not shown).

To examine whether the potential virulence factor Mip protein is involved in the induction of apoptosis, mip mutant strains B8 and B10 were used for infection. The ladder pattern of DNA fragmentation in HL-60 cells induced by the mip mutant strains were similar to these induced by the parental strains (Fig. 4b). These results suggest that Mip protein of $L$. longbeachae is not involved in the induction of apoptosis of HL-60 cells.

Apoptosis of the macrophage-like HL-60 cells was also assessed by flow cytometry after staining with fluorescein-conjugated annexin V and PI. In normal cells, PS is located in the inner leaflet of the cell membrane bilayer. The surface expression of PS is an early feature of apoptosis and occurs before the loss of membrane integrity. Cells in the early apoptotic process bind annexin $\mathrm{V}$ which has high affinity for PS, but exclude PI, while those in the late process or necrotic cells stain simultaneously with annexin V and PI. Macrophage-like HL-60 cells were infected with L. longbeachae ATCC 33462 at MOIs of 10 and 100 . At several time points after infection, cells were labelled with fluorescein-conjugated annexin V and PI and the quantity of label was determined by random 


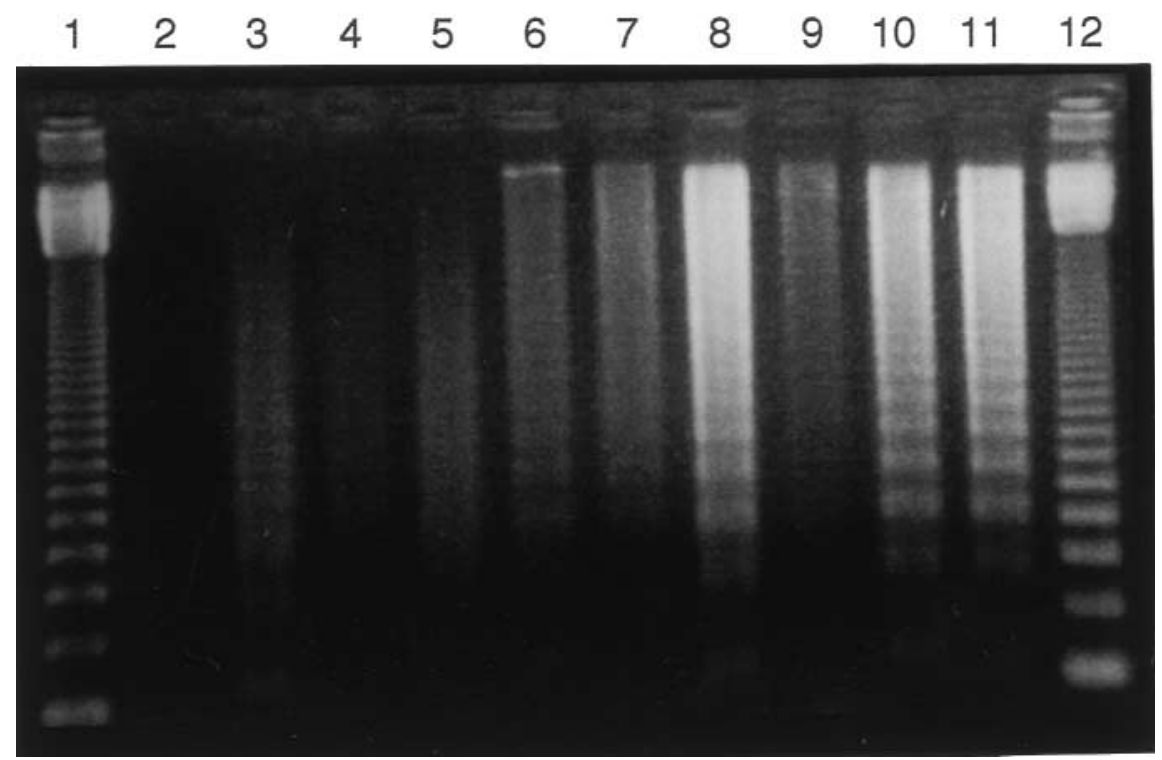

Fig. 3. Induction of internucleosomal DNA cleavage by infection of HL-60 cells with L. longbeachae ATCC 33462. Cellular DNA was isolated 24 or $48 \mathrm{~h}$ after infection from macrophage-like HL-60 cells infected with L. longbeachae ATCC 33462 at MOIs of 10 or 100. Lanes 1 and 12, molecular size marker (123 bp); 2 (24 h) and 7 (48 h), cellular DNA from uninfected HL-60 cells; 4 $(24 \mathrm{~h})$ and 9 (48 h), cellular DNA from HL-60 cells infected with heat-inactivated bacteria; 3 (24 h) and 8 (48 h), cellular DNA from actinomycin D-treated $(1 \mu \mathrm{g} / \mathrm{ml}) \mathrm{HL}-60$ cells. $5(24 \mathrm{~h})$ and $\mathbf{1 0}(48 \mathrm{~h})$, cellular DNA from HL-60 cells infected at a MOI of $10 ; 6(24 \mathrm{~h})$ and $11(48 \mathrm{~h})$, cellular DNA from HL-60 cells infected at a MOI of 100.

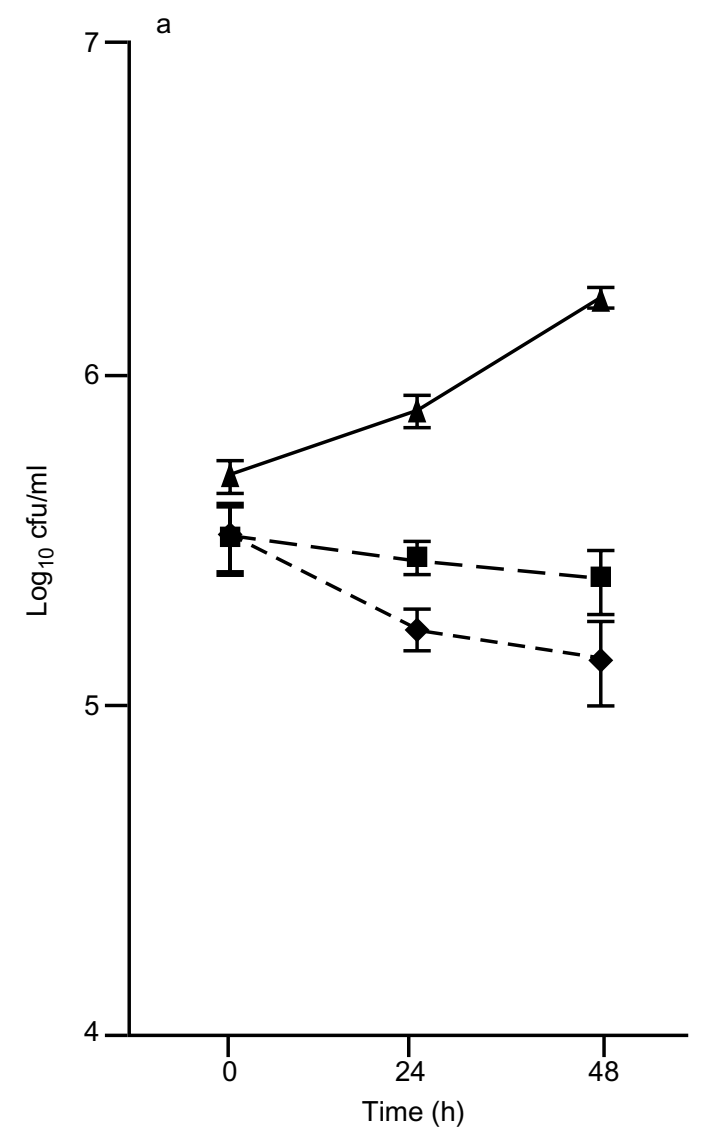

b

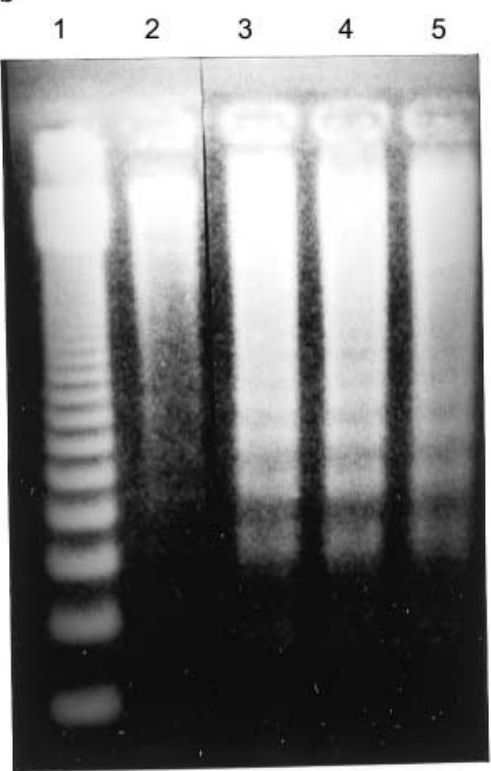

Fig. 4. (a) Intracellular growth kinetics of macrophage-like HL-60 cells infected with L. longbeachae strain A5H5 ( $\mathbf{\Delta})$ and the mip mutant strains B8 $(\boldsymbol{\square})$ and B10 $(\bullet)$. Cells were infected at a MOI of 100 and incubated for $48 \mathrm{~h}$. Data are means and SD of triplicate samples. (b) DNA fragmentation in HL-60 cells. Lane 1, 123-bp molecular size marker; 2, uninfected cells; 3, DNA from HL-60 cells infected with strain A5H5; 4, DNA from HL-60 cells infected with strain B8; 5, DNA from HL-60 cells infected with strain B10. 
counting of $5 \times 10^{3}$ cells. As shown in Fig. 5, the maximal percentage of early apoptotic cells was noted at $6 \mathrm{~h}$ after infection at different MOIs (MOI 10: 21.5\%; MOI 100: 28.5\%). The results of confocal microscopic examination (not shown) were similar to those of flow cytometric analysis. In the late stage of infection ( $48 \mathrm{~h}$ after infection) the percentage of late apoptotic cells and necrotic cells had increased, especially with the higher MOI (MOI 10: from 0.6 to 20.8\%; MOI 100: from 2.5 to $39.1 \%$ ). Based on these results, L. longbeachae-induced apoptosis was dosedependent. DNA fragmentation demonstrated by agarose gel electrophoresis also showed that induction of apoptosis was dose-dependent (Fig. 3).

Apoptosis of infected cells was induced during the early stage of infection, before intracellular bacterial replication. Intracellular replication of the mip mutants in infected cells was not observed even at $48 \mathrm{~h}$ after infection, whereas DNA fragmentation of infected cells

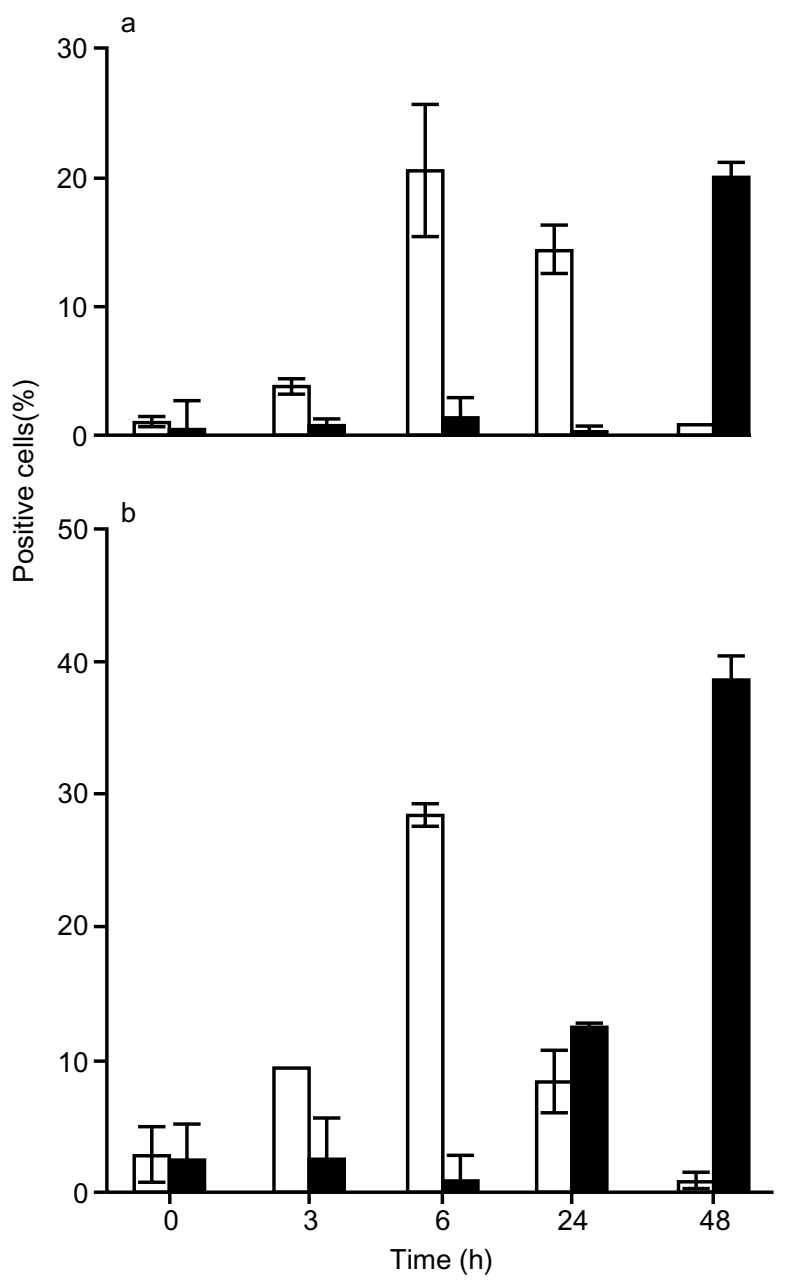

Fig. 5. Quantification of apoptosis in L. longbeachae-infected macrophage-like HL-60 cells by flow cytometry. Cell monolayers were infected at MOIs of 10 and 100 and labelled simultaneously with fluorescein-conjugated annexin V and PI; $5 \times 10^{3}$ cells were counted at random and data are expressed as percentage means and SD of triplicate samples. Similar results were obtained in two independent experiments. The numbers of annexin-positive cells $(\square)$ and annexin and PIpositive cells ( $\mathbf{\square})$ are shown. was observed by agarose gel electrophoresis (Fig. 4). These results suggested that intracellular bacterial replication is not required for induction of apoptosis of HL-60 cells.

\section{Mediation of L. longbeachae-induced apoptosis by activation of the caspase cascade}

To determine the involvement of caspases in L. longbeachae-induced apoptosis, HL-60 macrophages were treated with a broad-spectrum, cell-permeable, caspase inhibitor (Z-VAD-FMK) for $90 \mathrm{~min}$, at a concentration of $100 \mu \mathrm{M}$. Monolayer cells were infected with strain ATCC 33462 at a MOI of 100 for $2 \mathrm{~h}$ in the presence of the inhibitor, washed three times to remove unattached extracellular bacteria and incubated for a further $6 \mathrm{~h}$ in the presence of the inhibitor. DNA was isolated at the end of the 6-h incubation period and examined by agarose gel electrophoresis for detection of DNA fragmentation. DNA fragmentation in $L$. longbeachae-infected HL-60 cells was completely blocked by Z-VAD-FMK (Fig. 6).

Certain cytokines of the TNF ligand family and their receptors, including TNF- $\alpha$ receptor and Fas (also known as Apo-1 or CD95), are potent triggers of apoptosis in many cells [30]. TNF- $\alpha$ and Fas ligands induce apoptosis by binding to their respective death domain-containing receptors, TNF-RI and Fas [31]. TNF- $\alpha$ is secreted in the lung during L. pneumophila

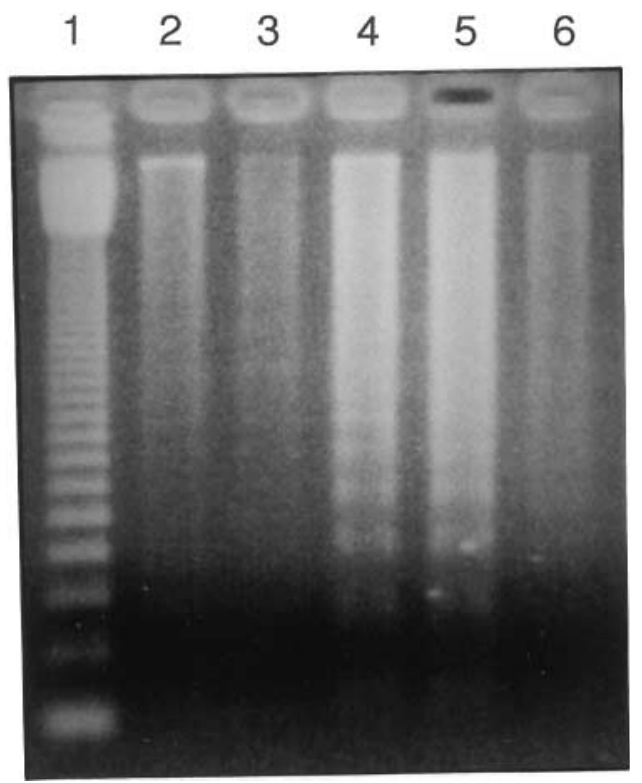

Fig. 6. Inhibition of DNA fragmentation in L. longbeachaeinfected HL-60 macrophages by caspase inhibitor Z-VADFMK. Cell monolayers were treated with $100 \mu \mathrm{M}$ Z-VADFMK for 90 min then infected with ATCC 33462 at MOIs of 10 and 100 for $2 \mathrm{~h}$ in the presence of Z-VAD-FMK. Cells were washed to remove extracellular bacteria and incubated for a further $6 \mathrm{~h}$ in the presence of Z-VAD-FMK-Lane 1, 123-bp molecular size marker; 2, Z-VAD-FMK-treated cells at a MOI of $100 ; 3, \mathrm{Z}$-VAD-FMK-treated cells at a MOI of $10 ; 4, \mathrm{Z}-$ VAD-FMK-untreated cells at MOI of $100 ; 4$, Z-VAD-FMKuntreated cells at a MOI of $10 ; \mathbf{5}$, uninfected cells. 
infection and inhibits growth of L. pneumophila in vivo in the lung and in vitro [32]. As shown in Fig. 7a, TNF- $\alpha$ production was significantly increased in L. longbeachae-infected HL-60 macrophages. To determine whether TNF- $\alpha$ is involved in triggering the death signal in L. longbeachae-infected HL-60 macrophages, the cells were treated with anti-human TNF- $\alpha$ for $1 \mathrm{~h}$ before infection. TNF- $\alpha$ activity in the supernate of infected cells was inhibited by $95 \%$ up to $48 \mathrm{~h}$ after infection (Fig. 7a) and it was lower than in the supernate of uninfected cells. The addition of antihuman TNF- $\alpha$ did not inhibit apoptosis or necrosis of infected cells (Fig. 7b). The expression of Fas in infected cells was also examined by flow cytometry. A
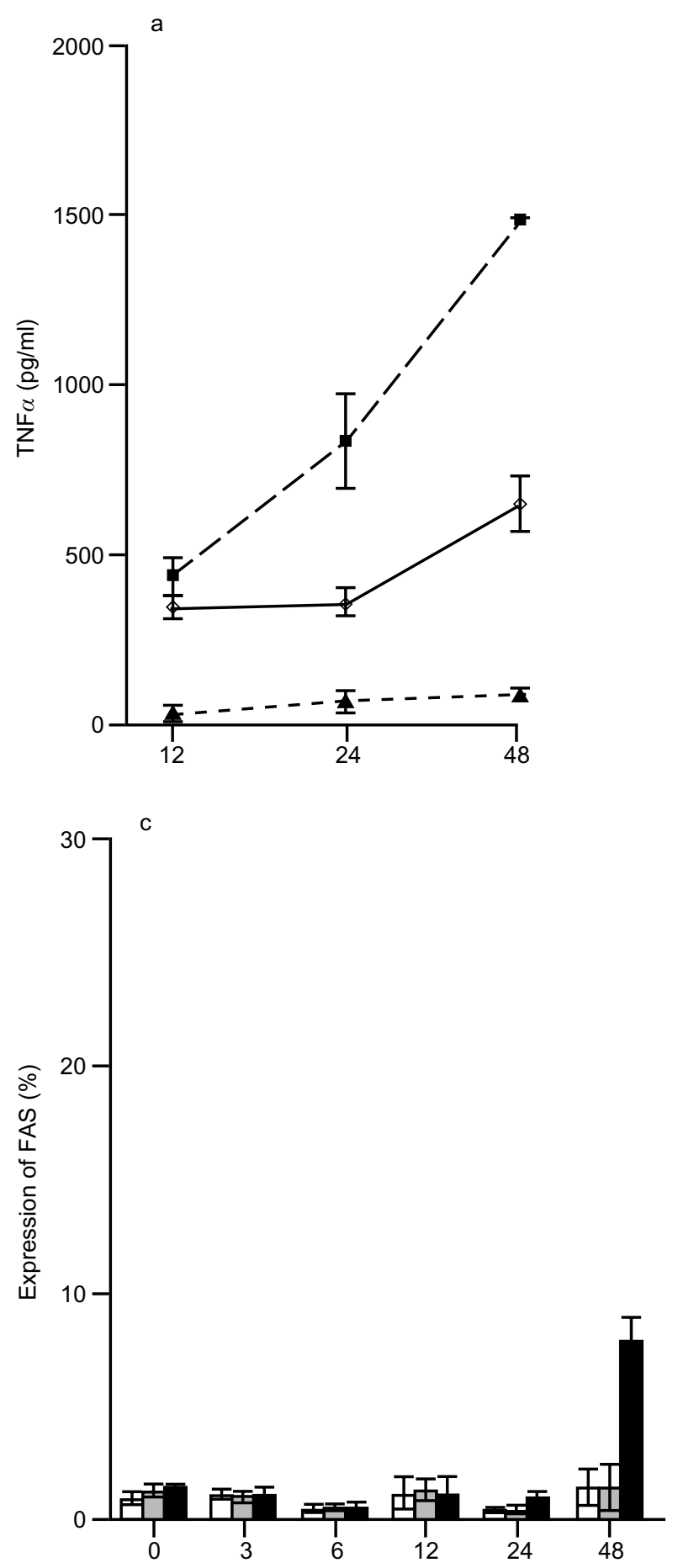

slight increase of Fas was noted on the surface of infected cells only at a late stage of apoptosis $(8.23 \%$ at $48 \mathrm{~h}$ after infection with a MOI of 100) (Fig. 7c). These results indicated that apoptosis of $L$. longbeachae-infected HL-60 macrophages does not seem to be dependent on TNF- $\alpha$ - and Fas-mediated pathways.

\section{Discussion}

Few studies have examined the virulence of $L$. longbeachae, an important causative organism of legionellosis [33]. L. longbeachae replicates within and is cytotoxic to macrophages $[9,34]$. Several recent

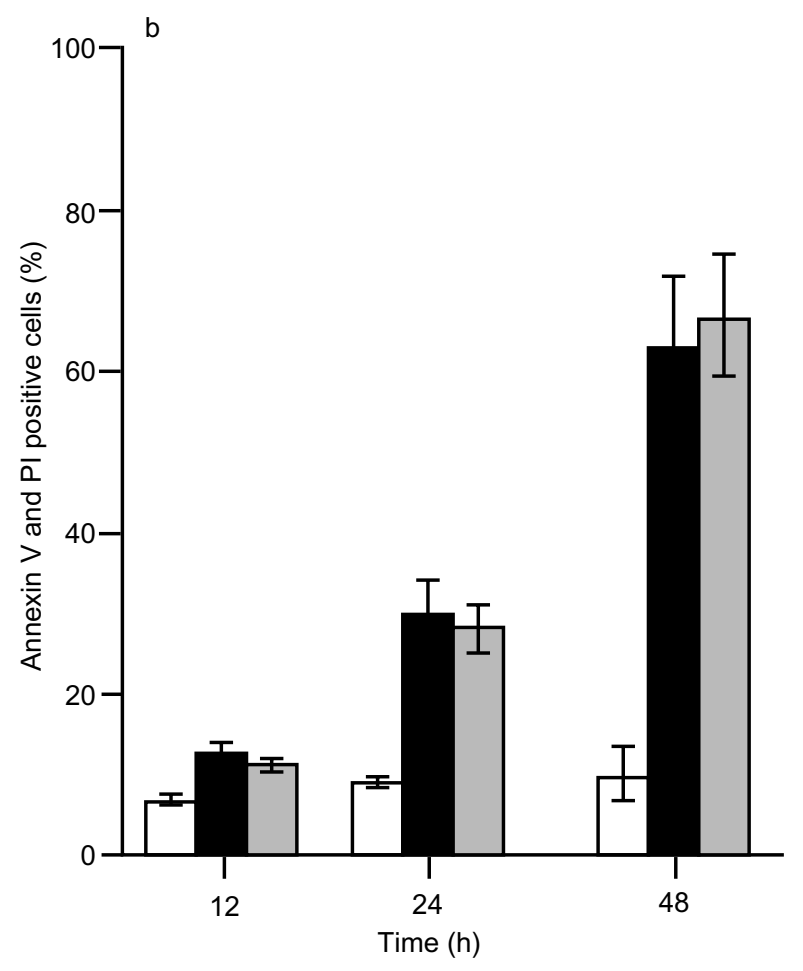

Fig. 7. Induction of apoptosis in L. longbeachae-infected HL60 macrophages is not mediated by TNF- $\alpha$ and FAS. (a) TNF$\alpha$ concentration in cell culture supernates of uninfected cells $(\diamond)$, infected cells $(\square)$, and infected cells pretreated with antihuman TNF- $\alpha$ antibody ( $\boldsymbol{\Delta}$ ). (b) Percentage of apoptotic cells. (c) Expression of Fas-positive cells. In (b) and (c), uninfected cells are represented by $\square$, cells infected at MOI of 100 by and infected cells pretreated with anti-human TNF- $\alpha$ antibody by $\square$. Data are expressed as percentage means and SD of triplicate samples. Similar results were obtained in two independent experiments. 
studies have investigated the mechanisms of cell death induced by L. pneumophila [24, 25, 35, 36]. Müller et al. [24] showed that L. pneumophila could induce apoptosis of HL-60 macrophages at $24 \mathrm{~h}$ and $48 \mathrm{~h}$ after infection. Furthermore, Gao et al. [25] reported that L. pneumophila induced apoptosis of macrophages and epithelial cells during the early stage of infection at MOIs of $0.5,5$ and 50. They concluded that induction of apoptosis by L. pneumophila correlated with cytotoxicity. However, the cytotoxicity and the mechanisms of host cell death due to infection by other Legionella spp. has not been well examined. The present study investigated whether $L$. longbeachae could multiply within human macrophages and could be cytotoxic, and whether L. longbeachae infection could induce apoptosis of macrophage-like HL-60 cells. Various criteria of apoptosis were used, including DNA fragmentation, flow cytometric analysis, and terminal deoxyribonucleotidyl transferase-mediated triphosphate (dUTP)-biotin nick end labelling (TUNEL; data not shown) to confirm for the first time that L. longbeachae induced apoptosis of these cells. L. longbeachae induced apoptosis after a few hours of infection at MOIs of 10 and 100. Viability of bacteria is also an essential feature of L. longbeachaeinduced apoptosis of host cells. Mip mutant strains of L. longbeachae could induce apoptosis of macrophages, despite their defective intracellular replication. Recent studies have shown that Mip protein plays an important role in the intracellular life cycle of $L$. longbeachae and is required for full virulence [5]. However, the data from the present study suggested that Mip protein was not essential for the induction of apoptosis of macrophages. Gao et al. [25] examined 46 pmi (protozoan and macrophage infectivity loci) mutants of L. pneumophila that were defective, to various degrees, in intracellular replication within host cells. Among them, dotA and icmWXYZ mutants were completely defective in induction of apoptosis and cytotoxicity, suggesting that dot and icm express possible apoptosis-inducing factors [25]. Thus, further studies of the dot and icm homologues in L. longbeachae are warranted.

Several recent studies have demonstrated that apoptosis plays an important role in local immune responses against micro-organisms. Several pathogens, including Sh. flexneri [13], Yersinia enterocolitica [37], Bordetella pertussis [38], A. actinomycetemcomitans [17], Listeria monocytogenes [39], M. tuberculosis [20, 40] and S. Typhimurium [15], promote the destruction of monocytic phagocytes by apoptosis, to destroy the host immune system and promote the development of infection. On the other hand, some intracellular bacteria such as M. bovis [22], Chlamydiae [41], Rickettsia rickettsii and $B r$. suis [23], inhibit apoptosis to protect themselves from the host immune system, and to multiply in host cells. Gross et al. [23] suggested that intracellular bacteria use two strategies, the first is inhibition of apoptosis which enhances their survival and replication within phagocytes, as well as their continued presence at the site of infection. Another group of bacteria including L. pneumophila, promotes apoptosis of phagocytes and finally reaches epithelial cells [25]. In this study, apoptosis induced by L. longbeachae did not inhibit bacterial multiplication. Further studies are necessary to examine bacterial growth in macrophages treated with various inhibitors of apoptosis.

Following confirmation of $L$. longbeachae-induced apoptosis, the mechanisms of this process, including the role of the caspase cascade were investigated. The caspase family of cysteine proteases is known to play important roles in regulation of apoptosis and the inflammatory response [42]. Sh. flexneri-induced apoptosis of macrophages not only permits bacterial survival but also triggers inflammation [43]. Invasion plasmid antigen B (Ipa B), which is secreted from $S h$. flexneri, binds to caspase-1 (interleukin (IL)- $1 \beta$ converting enzyme) and activates the enzyme. The activated enzyme converts pro IL- $1 \beta$ to IL- $1 \beta$, and also allows magnification of the inflammation cascade [44]. Y. enterocolitica-induced apoptosis is independent of caspase-1, but a broad-spectrum caspase inhibitor still blocks the completion of the Yersinia-induced apoptotic programme [37]. However, Chlamydia psittaci-induced apoptosis is independent of either proapoptotic caspase-1 or caspase-3 [44]. In the present study, the broad-spectrum caspase inhibitor, Z-VADFMK, completely blocked induction of apoptosis of L. longbeachae-infected HL-60 macrophages. This result is similar to the findings in L. pneumophilainduced apoptosis in macrophages [25]. In this study, pro-inflammatory cytokines, such as TNF- $\alpha$ (Fig. 7a) and IL-1 $\beta$ (data not shown), were released by $L$. longbeachae-infected macrophages. However, the role of these released cytokines in L. longbeachae infection remains to be determined. TNF- $\alpha$ is known to activate mononuclear phagocytes to inhibit intracellular parasites [45] and to potentiate the antimicrobial action of interferon (IFN)- $\gamma$ [46]. Furthermore, L. pneumophila induces TNF- $\alpha$ secretion in vitro and in vivo [32], suggesting a potential role for this cytokine in host defence in legionellosis [47].

TNF- $\alpha$ and Fas are well known as common death signals, but other death signalling pathways have been reported $[48,49]$. Apoptosis of L. pneumophilainfected monocytes is independent of the TNF- $\alpha$ mediated pathway [36]. Host cell death by other organisms such as C. psittaci [44] and Entamoeba histolytica [50] does not involve Fas and TNF- $\alpha$ pathways. The results of the present study also suggested that $L$. longbeachae-induced apoptosis is independent of both TNF- $\alpha$ - and Fas-mediated pathways.

In conclusion, L. longbeachae-infected HL-60 cells undergo apoptosis during the early stages of infection 
and induction of apoptosis plays an important role in cytotoxicity. Furthermore, induction of apoptosis of L. longbeachae-infected macrophages was mediated by activation of the caspase pathway but might be independent of TNF- $\alpha$ - and Fas-mediated signal transduction pathways. Further studies are necessary to determine the bacterial factor(s) that induce apoptosis, which is potentially involved in L. longbeachae pathogenesis.

We thank Dr F. G. Issa for reading and editing the manuscript. This study was funded by a Grant in Aid from the Japanese Ministry of Health and Welfare.

\section{References}

1. McKinney RM, Porschen RK, Edelstein PH et al. Legionella longbeachae species nova, another etiologic agent of human pneumonia. Ann Intern Med 1981; 94: 739-743.

2. Lim I, Sangster N, Reid DP, Lanser JA. Legionella longbeachae pneumonia: report of two cases. Med J Aust 1989; 150: $599-601$

3. Cameron S, Roder D, Walker C, Feldheim J. Epidemiological characteristics of Legionella infection in South Australia: implications for disease control. Aust NZ J Med 1991; 21: 65-70.

4. Lanser JA, Adams M, Doyle R, Sangster N, Steele TW. Genetic relatedness of Legionella longbeachae isolates from human and environmental sources in Australia. Appl Environ Microbiol 1990; 56: 2784-2790.

5. Doyle RM, Steele TW, McLennan AM, Parkinson IH, Manning PA, Heuzenroeder MW. Sequence analysis of the mip gene of the soilborne pathogen Legionella longbeachae. Infect Immun 1998; 66: 1492-1499.

6. Steele TW, Lanser J, Sangster N. Isolation of Legionella longbeachae serogroup 1 from potting mixes. Appl Environ Microbiol 1990; 56: 49-53.

7. Steele TW. Interaction between soil amoebae and soil legionellae. In: Barbaree JM, Breiman RF, Dufour AP (eds) Legionella: current status and emerging perspectives. Washington, DC, American Society for Microbiology. 1993: 140-142.

8. Okazaki M, Umeda B, Koide M, Saito A. [Legionella longbeachae pneumonia in a gardener.] Kansenshogaku Zasshi 1998; 72: 1076-1079.

9. Koide M, Saito A, Okazaki M, Umeda B, Benson RF. Isolation of Legionella longbeachae serogroup 1 from potting soils in Japan. Clin Infect Dis 1999; 29: 943-944.

10. Cianciotto NP, Eisenstein BI, Mody CH, Toews GB, Engleberg NC. A Legionella pneumophila gene encoding a speciesspecific surface protein potentiates initiation of intracellular infection. Infect Immun 1997; 57: 1255-1262.

11. Cianciotto NP, Eisenstein BI, Mody CH, Engleberg NC. A mutation in the mip gene results in an attenuation of Legionella pneumophila virulence. J Infect Dis 1990; 162: $121-126$.

12. Fischer G, Bang H, Ludwig B, Mann K, Hacker J. Mip protein of Legionella pneumophila exhibits peptidyl-prolyl-cis/trans isomerase (PPlase) activity. Mol Microbiol 1992; 6: 13751383.

13. Zychlinsky A, Prevost MC, Sansonetti PJ. Shigella flexneri induces apoptosis in infected macrophages. Nature 1992; 358: $167-169$.

14. Zychlinsky A, Sansonetti PJ. Apoptosis as a proinflammatory event: what can we learn from bacteria-induced cell death? Trends Microbiol 1997; 5: 201-204.

15. Lindgren SW, Stojiljkovic I, Heffron F. Macrophage killing is an essential virulence mechanism of Salmonella typhimurium. Proc Natl Acad Sci USA 1996; 93: 4197-4201.

16. Kochi SK, Collier RJ. DNA fragmentation and cytolysis in U937 cells treated with diphtheria toxin or other inhibitors of protein synthesis. Exp Cell Res 1993; 208: 296-302.

17. Kato S, Muro M, Akifusa S et al. Evidence for apoptosis of murine macrophages by Actinobacillus actinomycetemcomitans infection. Infect Immun 1995; 63: 3914-3919.
18. Hanna PC, Acosta D, Collier RJ. On the role of macrophages in anthrax. Proc Natl Acad Sci USA 1993; 90: 10198-10201.

19. Tsai P-J, Lin Y-S, Kuo C-F, Lei H-Y, Wu J-J. Group A Streptococcus induces apoptosis in human epithelial cells. Infect Immun 1999; 67: 4334-4339.

20. Keane J, Balcewicz-Sablinska MK, Remold HG et al. Infection by Mycobacterium tuberculosis promotes human alveolar macrophage apoptosis. Infect Immun 1997; 65: 298-304.

21. Dürrbaum-Landmann I, Gercken J, Flad H-D, Ernst M. Effect of in vitro infection of human monocytes with low numbers of Mycobacterium tuberculosis bacteria on monocyte apoptosis. Infect Immun 1996; 64: 5384-5389.

22. Kremer L, Estaquier J, Brandt E, Ameisem J-C, Lodit C. Mycobacterium bovis Bacillus Calmette Guérin infection prevents apoptosis of resting human monocytes. Eur $J$ Immunol 1997; 27: 2450-2456.

23. Gross A, Terraza A, Ouahrani-Bettache S, Liautard J-P, Dornand J. In vitro Brucella suis infection prevents the programmed cell death of human monocytic cells. Infect Immun 2000; 68: 342-351.

24. Müller A, Hacker J, Brand BC. Evidence for apoptosis of human macrophage-like HL-60 cells by Legionella pneumophila infection. Infect Immun 1996; 64: 4900-4906.

25. Gao L-Y, Abu Kwaik Y. Apoptosis in macrophages and alveolar epithelial cells during early stages of infection by Legionella pneumophila and its role in cytopathogenicity. Infect Immun 1999; 67: 862-870.

26. Saito A, Sawatari K, Fukuda Y et al. Susceptibility of Legionella pneumophila to ofloxacin in vitro and in experimental Legionella pneumonia in guinea pigs. Antimicrob Agents Chemother 1985; 28: 15-20.

27. Collins SJ, Ruscetti FW, Gallagher RE, Gallo RC. Terminal differentiation of human promyelocytic leukemia cells induced by dimethyl sulfoxide and other polar compounds. Proc Natl Acad Sci USA 1978; 75: 2458-2462.

28. McCarthy NJ, Whyte MKB, Gilbert CS, Evan GI. Inhibition of Ced-3/ICE-related proteases does not prevent cell death induced by oncogenes, DNA damage, or the Bcl-2 homologue Bak. J Cell Biol 1997; 136: 215-227.

29. Raynal P, Pollard HB. Annexins: the problem of assessing the biological role for a gene family of multifunctional calciumand phospholipid-binding proteins. Biochim Biophys Acta 1994; 1197: 63-93.

30. Mizuno K, Noda K, Araki T et al. The proteolytic cleavage of protein kinase $\mathrm{C}$ isotypes, which generates kinase and regulatory fragments, correlates with Fas-mediated and 12-Otetradecanoyl-phorbol-13-acetate-induced apoptosis. Eur J Biochem 1997; 250: 7-18.

31. Pan G, O'Rourke K, Chinnaiyan AM et al. The receptor for the cytotoxic ligand TRAIL. Science 1997; 276: 111-113.

32. Blanchard DK, Djeu JY, Klein TW, Friedman H, Stewart WE. Induction of tumor necrosis factor by Legionella pneumophila. Infect Immun 1987; 55: 433-437.

33. Nimmo GR, Bull JZ. Comparative susceptibility of Legionella pneumophila and Legionella longbeachae to 12 antimicrobial agents. J Antimicrob Chemother 1995; 36: 219-223.

34. Neumeister B, Reiff G, Faigle M, Dietz K, Northoff H, Lang F. Influence of Acanthamoeba castellanii on intracellular growth of different Legionella species in human monocytes. Appl Environ Microbiol 2000; 66: 914-919.

35. Gao L-Y, Abu Kwaik Y. Activation of caspase 3 during Legionella pneumophila-induced apoptosis. Infect Immun 1999; 67: 4886-4894.

36. Hägele S, Hacker J, Brand BC. Legionella pneumophila kills human phagocytes but not protozoan host cells by inducing apoptotic cell death. FEMS Microbiol Lett 1998; 169: 51-58.

37. Ruckdeschel K, Roggenkamp A, Lafont V, Mangeat P, Heesemann J, Rouot B. Interaction of Yersinia enterocolitica with macrophages leads to macrophage cell death through apoptosis. Infect Immun 1997; 65: 4813-4821.

38. Khelef N, Zychlinsky A, Guiso N. Bordetella pertussis induces apoptosis in macrophages: role of adenylate cyclase-hemolysin. Infect Immun 1993; 61: 4064-4071.

39. Rogers HW, Callery MP, Deck B, Unanue ER. Listeria monocytogenes induces apoptosis of infected hepatocytes. J Immunol 1996; 156: 679-684.

40. Keane J, Remold HG, Kornfeld H. Virulent Mycobacterium tuberculosis strains evade apoptosis of infected alveolar macrophages. J Immunol 2000; 164: 2016-2020. 
41. Fan $\mathrm{T}, \mathrm{Lu} \mathrm{H}, \mathrm{Hu} \mathrm{H}$ et al. Inhibition of apoptosis in chlamydiainfected cells: blockade of mitochondrial cytochrome c release and caspase activation. J Exp Med 1998; 187: 487-496.

42. Salvesen GS, Dixit VM. Caspases: intracellular signaling by proteolysis. Cell 1997; 91: 443-446.

43. Chen Y, Smith MR, Thirumalai K, Zychlinsky A. A bacterial invasin induces macrophage apoptosis by binding directly to ICE. EMBO J 1996; 15: 3853-3860.

44. Ojcius DM, Souque P, Perfettini J-L, Dautry-Varat A Apoptosis of epithelial cells and macrophages due to infection with the obligate intracellular pathogen Chlamydia psittaci. J Immunol 1998; 161: 4220-4226.

45. De Titto EH, Catterall JR, Remington JS. Activity of recombinant tumor necrosis factor on Toxoplasma gondii and Trypanosoma cruzi. J Immunol 1986; 137: 1342-1345.

46. Chang HR, Grau GE, Pechère JC. Role of TNF and IL-1 in infections with Toxoplasma gondii. Immunology 1990; 69: 33-37. 47. Skerrett SJ, Martin TR. Roles for tumor necrosis factor alpha and nitric oxide in resistance of rat alveolar macrophages to Legionella pneumophila. Infect Immun 1996; 64: 3236-3243.

48. Dudich E, Semenkova L, Dudich I et al. Alpha-fetoprotein causes apoptosis in tumor cells via a pathway independent of CD95, TNFR1 and TNFR2 through activation of caspase-3-like proteases. Eur J Biochem 1999; 266: 750-761.

49. Fleck M, Mountz JD, Hsu HC, Wu J, Edwards CK, Kern ER. Herpes simplex virus type 2 infection induced apoptosis in peritoneal macrophages independent of Fas and tumor necrosis factor-receptor signaling. Viral Immunol 1999; 12: 263-275.

50. Seydel KB, Stanley SL. Entamoeba histolytica induces host cell death in amebic liver abscess by a non-Fas-dependent, non-tumor necrosis factor alpha-dependent pathway of apoptosis. Infect Immun 1998; 66: 2980-2983. 